\title{
Medical Outcomes Study Social Support Survey
}

National Cancer Institute

\section{Source}

National Cancer Institute. Medical Outcomes Study Social Support Survey. NCI

Thesaurus. Code C110969.

A survey of multiple dimensions of social support. 